\title{
Effect of Ag, In and AgIn Alloying Additions on Microstructure and Texture of Mg-3Al-1Zn Alloy during Multi-Pass Warm Rolling
}

\author{
JAWED Kamran ${ }^{1, a,}$, BIN Awais Hasan ${ }^{1}$, NAEEM UL HAQ Tariq ${ }^{1}$ \\ and YIN Wang ${ }^{2}$
}

${ }^{1}$ Department of Metallurgy and Materials Engineering, Pakistan Institute of Engineering and Applied Sciences (PIEAS), Nilore, Islamabad, Pakistan

${ }^{2}$ School of Materials, Faculty of Engineering and Physical Science, The University of Manchester, Grosvenor Street, Manchester, M1 7HS, UK

ajawedkamran@hotmail.com

Keywords: Texture, Warm Rolling, Magnesium Alloy.

Abstract. In the present investigation the rolling response, microstructure and texture evolution of four $\mathrm{Mg}$ alloys during multi-pass warm rolling were evaluated. The nominal composition of the base alloy i.e. 'alloy-1', commercially called AZ31, was Mg-3Al-1Zn (wt.\%). The alloy-2, 3 and 4 were developed by separate additions of non-rare earth elements $\mathrm{Ag}$ and In, and a master alloy 85Ag-15In to make target compositions Mg-3Al-1Zn-0.5x, $(\mathrm{x}=\mathrm{Ag}$, In, AgIn). Samples from all four alloys were subjected to multi-pass warm rolling at $300{ }^{\circ} \mathrm{C}$ to accumulative reductions of 50 , 75 and $90 \%$ with 8 minutes inter-pass annealing. For all four alloys, crack free sheets of less than $1 \mathrm{~mm}$ thickness were produced successfully with true strain corresponding to $90 \%$ reduction. The as-cast microstructures revealed second phase particles at grain boundaries and grains interiors for all alloys. A slight scatter in the size of the deformed grains was observed for alloy-1, 2 and 3 after rolling reductions of 50,75 and 90\%. However, a sustained decrease in grain size with increasing the rolling reductions was only observed in alloy-4, despite inter-pass annealing. XRD macrotexture results of alloy- 2 and 3 presented very strong basal texture showing almost concentric contours around normal direction (ND). Such strong sheet texture is attributed to a preferential alignment of basal planes parallel to the sheet surface. On the other hand alloy-1 and alloy-4 revealed a weaker texture with basal poles spread more towards transverse direction (TD) as compared to rolling direction (RD) and may be due to the activation of some $<c+a>$ non-basal slip and twinning in addition to basal slip under the same processing parameters.

\section{Introduction}

Among the abundant and relatively inexpensive light metals, Mg-based alloys are 2/3rd times lighter than Al-base alloys which are currently the main structural material used in automotive and aerospace industry. Apart from their low density, Mg-alloys have several other attractive engineering properties like, high specific strength, good machinability, high damping capacity, good castability [1-4]. However, due to their HCP structure Mg-alloys are difficult to process thermo-mechanically. Another obstacle to the formability of the magnesium sheet production is the formation of strong basal texture [5-8]. For automotive and aerospace applications, Mg-alloys have a potential to save substantial amount of fuel. After the advances in characterization tools, there is a scientific resurgence in finding the deformation mechanisms in wrought Mg-alloys [9-14]. Great attention was paid to improve their forming properties and to weaken the (0002) basal texture. The research efforts, in this regard, could be classified into two main streams [15]. The first category includes all conventional deformation processes where focus is on intelligent thermomechanical processing for texture modification. This includes, deformation at different combinations of temperature [16] and strain rate [17], cold [18], warm [19] and hot processing [20], multi-pass and single pass rolling with different roll-gaps [21], change of orientation during successive rolling steps and cross rolling [21] etc. The other stream belongs to the non-conventional severe plastic deformation (SPD) techniques like differential speed rolling DSR [22], equal channel angular 
extrusion (ECAE) [23], equal channel angular pressing (ECAP) [24], high pressure torsion (HPT) [25], cyclic loading-unloading (CLU) [26], friction stir processing (FSP) [27] and repeated unidirectional bending (RUB) [28] etc. Researchers have also reported the effect of alloying elements in Mg-based alloys [29,30]. Literature reports that these additions either refine the microstructure or alter the texture or influence both. For this purpose, mostly rare earth (RE) elements were used as an alloying addition [31]. However, the role of non-RE elements is less investigated. It has been reported that the texture weakening effect of RE elements is substantially magnified by the addition of other non-RE elements, such as $\mathrm{Zn}$ and $\mathrm{Zr}$ [15]. The alloying elements increase the formability of alloy either by grain refinement [32], by increasing the amount of recrystallization (RX) [33], changing the lattice parameters or by weakening the basal texture [34]. The alloying elements have to be chosen very carefully considering their solid solubility in $\mathrm{Mg}$. According to the Hume - Rothery rules, extensive solid solutions cannot be formed if the atomic sizes of the solvent and solute differ by more than $15 \%$. In the case of $\mathrm{Mg}$, which has an atomic diameter of $3.2 \AA$, the elements that fall in this favorable size range are $\mathrm{Li}, \mathrm{Al}, \mathrm{Ti}, \mathrm{Cr}, \mathrm{Zn}, \mathrm{Ge}, \mathrm{Yt}$, $\mathrm{Zr}, \mathrm{Nb}, \mathrm{Mo}, \mathrm{Pd}, \mathrm{Ag}, \mathrm{Cd}, \mathrm{In}, \mathrm{Sn}, \mathrm{Sb}, \mathrm{Te}, \mathrm{Nd}, \mathrm{Hf}, \mathrm{W}, \mathrm{Re}, \mathrm{Os}, \mathrm{Pt}, \mathrm{Au}, \mathrm{Hg}, \mathrm{Tl}, \mathrm{Pb}$ and Bi [35]. The highest solid solubility exists when size factors and relative valence are very favorable (up to $15 \%$ relative size, and valence of 2 or 3 ).

In the present work, the conventional $\mathrm{Mg}-3 \mathrm{Al}-1 \mathrm{Zn}$ alloy is modified with $0.5 \mathrm{wt} \%$ of different alloying elements namely $\mathrm{In}, \mathrm{Ag}$, and a master alloy of (Ag-In) to make novel alloy compositions. The present alloying addition of Ag shows $16 \%$ solid solubility where as In shows the maximum solid solubility as high as $53 \%$. The effect of alloying addition on microstructure and texture evolution was compared with a base $\mathrm{Mg}-3 \mathrm{Al}-1 \mathrm{Zn}$ alloy during multi-pass warm rolling reductions of 50,75 and $90 \%$.

\section{Experimental}

Alloy-1 with a nominal chemistry of Mg-3Al-1Zn was prepared from high purity $\mathrm{Mg}(99.99 \%)$, $\mathrm{Al}(99.99 \%)$ and $\mathrm{Zn}(99.99 \%)$ metals. The charge was melted in an iron crucible using an electrical resistance furnace. Alloy-2, alloy-3 and alloy-4 were prepared by separate additions of non-rare earth elements $\mathrm{Ag}$, In and a master alloy 85Ag-15In to the base alloy. The following target compositions were made: alloy-2 (Mg-3Al-1Zn-0.5Ag), alloy-3 (Mg-3Al-1Zn-0.5In), and alloy-4 (Mg-3Al-1Zn-0.5AgIn). After stabilization at $780{ }^{\circ} \mathrm{C}(1053 \mathrm{~K})$ for $5 \mathrm{~min}$, the melt was poured into a copper mold with dimension $80 \times 75 \times 8 \mathrm{~mm} 3$. All melting/ casting processes were performed under a dynamic flow of Ar gas (99.999\% pure) in a glove box by maintaining a relative humidity (RH) below 10\%. The cast ingots were demolded after cooling in Ar. A homogenization heat treatment at $400{ }^{\circ} \mathrm{C}(673 \mathrm{~K})$ for $12 \mathrm{hrs}$ in $\mathrm{Ar}$ atmosphere was then carried out. Chemical analysis of the homogenized samples was carried out using 'Thermofisher 6000' inductively coupled plasma (ICP) equipment.

The alloy ingots with a starting thickness of $7.38 \mathrm{~mm}$ were utilized for warm rolling at $300{ }^{\circ} \mathrm{C}$ $(573 \mathrm{~K})$. A Joliot two high rolling mill with roll diameter and roll length of 124 and $150 \mathrm{~mm}$ respectively was used for this purpose. Rolling speed was kept fixed at 27 rev.min-1 throughout the experiment. Prior to the start of rolling, all samples were preheated for 2 hours at $350{ }^{\circ} \mathrm{C}(623 \mathrm{~K})$ in Ar atmosphere. The alloys were subjected to multipass thickness reduction with inter-pass heating of 4 minutes. The samples for characterization of microstructures and macrotexture were collected after accumulative reduction of $50 \%, 75 \%$ and $90 \%$. A schematic of the thermo-mechanical process (TMP) is presented in Fig. 1.

For optical microscopy, all specimens were mechanically ground by using $\mathrm{SiC}$ papers from 1500 grit down to 4000 grit. Final polishing was performed by using an oxide particle suspension (OPS) polish. The polished specimens were etched for 1 to $5 \mathrm{sec}$, using an etchant composed of acetic acid $10 \mathrm{ml}$, acetic picral $4.25 \mathrm{~g}$, distilled water $10 \mathrm{ml}$ and ethanol $70 \mathrm{ml}$. The optical microscopy (OM) of the samples was performed on the rolling plane. The grain size was determined by the line intercept method according to ASTM standard E112-10. The XRD-macrotexture was determined by Schulz 
reflection method with $\mathrm{Cu} \mathrm{K \alpha}$ radiation using a Rigaku D/max-2500 diffractometer. Incomplete

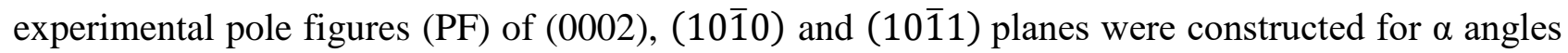
ranging from $15^{\circ}$ to $85^{\circ}$ in the sheet plane containing RD and TD. After making data correction for the background and intensity, the ODF was calculated to recalculate the complete pole figures of each sample using MTEX software.

\section{Alloying $\left(780^{\circ} \mathrm{C}\right)$}

Alloy-2: Mg-3Al-1Zn-0.5Ag

Alloy-3: Mg-3Al-1Zn-0.5ln

Alloy-4: Mg-3Al-1Zn-0.5Agln
Alloy-1: Mg-3Al-1Zn

Homogenizing

(400 $\left.{ }^{\circ} \mathrm{C}, 12 \mathrm{hrs}\right)$
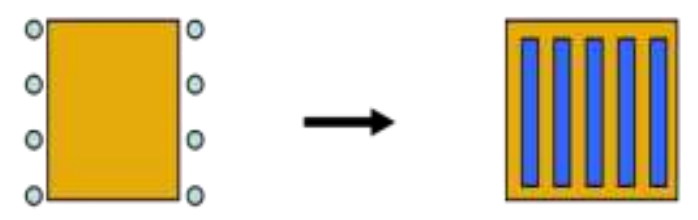

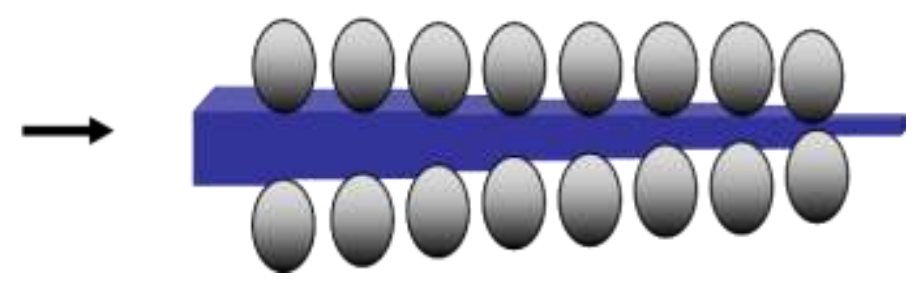

Fig. 1. Schematic illustration of the thermo-mechanical processing.

\section{Results and Discussion}

Warm Rolling Behavior. A 50\% reduction was achieved after 9 successive passes while the $75 \%$ reduction was achieved after 13 passes. The $90 \%$ reduction was accomplished in a further two steps. A special arrangement was to apply inter-pass annealing of 8 minutes at the warm rolling temperature of $300{ }^{\circ} \mathrm{C}$, between each successive passes to circumvent the effect of strain hardening. All the alloy samples were successfully rolled without surface or edge cracking after 50, 75 and $90 \%$. Successful rolling by multi-pass rolling in present investigation is in agreement with the observation made for AZ31 by previous researcher [36]. It seems that the chosen process parameters are responsible for the successful rolling. The effect of alloying additions on rolling response could not be explicitly determined as all alloys were successfully rolled. As regarding the surface finish of the four alloys, the alloy- 4 showed a superior smoother surface as compared to all other alloy corresponding to all true strains.

As-cast Microstructures. The microstructures of alloy-1, 2, 3 and 4 in the as-cast condition are shown in Fig. 2. The microstructures of all four alloys revealed equiaxed grains. Some second phase particles, in black contrast, are also visible in all alloys. These particles were found more in the grain interiors in alloy-1 Fig. 2(a) and alloy-3 Fig. 2(c). On the other hand, the presence of second phase particles both at grain boundary and within the grains are clearly visible in alloy-2 Fig. 2(b) and alloy-4 Fig. 2(d). The alloying elements that have high solid solubility with $\mathrm{Mg}$, results in precipitates that are usually observed at grain boundaries and within the grains. It is reported that rare-earth element Neodymium when added into $\mathrm{Mg}$ triggers at grains boundaries and within the grains [37,38]. Literature reports that besides $\alpha-\mathrm{Mg}$ matrix, there are two additional phases form in commercial AZ31 Mg alloy. These phases are: a binary $\mathrm{Mg}-\mathrm{Al}$ phase (Mg17Al12) and a $\mathrm{Mn}$-rich Al-Mn grain phase [39,40]. It has been reported that $\mathrm{Mn}$ reacts with Al to form Al-Mn grain boundary precipitates in commercial AZ31 magnesium alloy. The particles observed within grains of alloy-1 may be Mg17Al12 phase due to absence of Mn in the present study. This phase is reported to be stable below $200{ }^{\circ} \mathrm{C}$ as shown in [41]. 

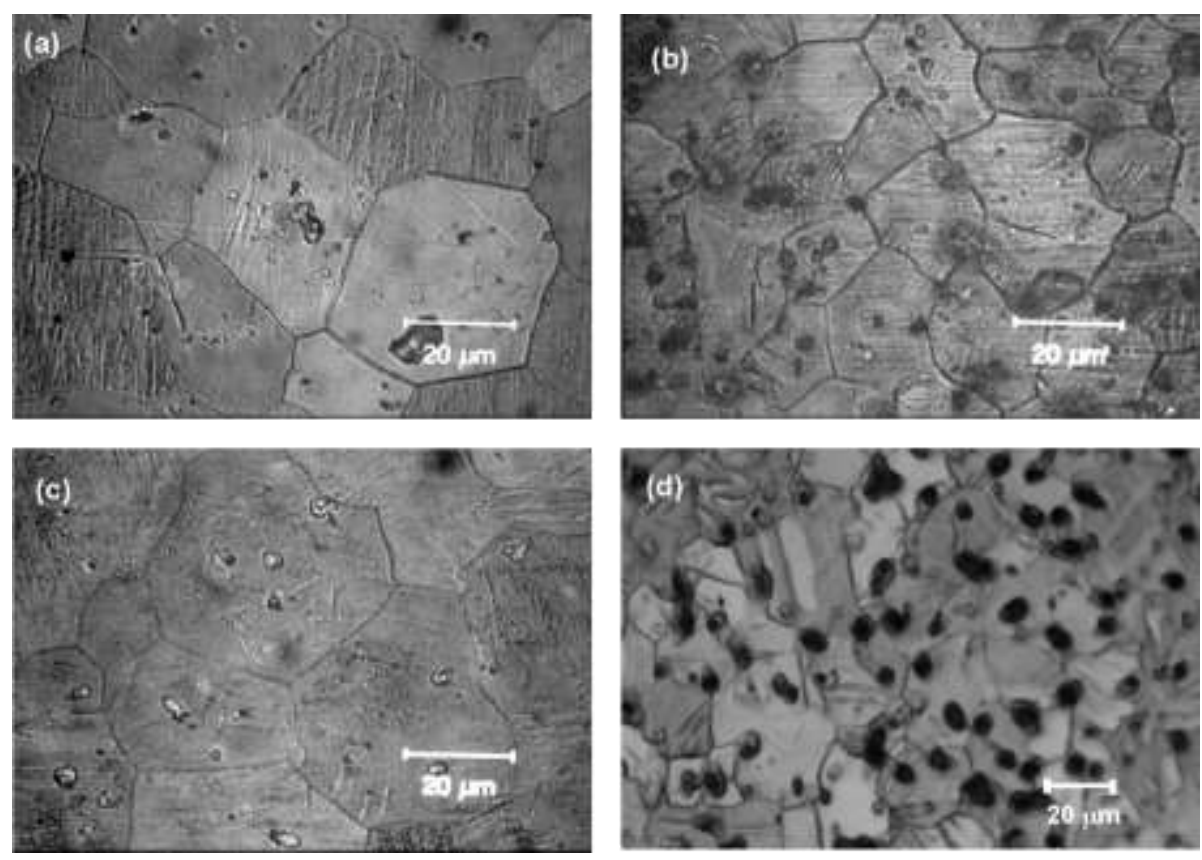

Fig. 2. As-cast microstructures of alloys (a) alloy-1, (b) alloy-2, (c) alloy-3, and (d) alloy-4.

Alloy-1 showed an average grain size of $\sim 3 \mu \mathrm{m}$ while alloy-2, 3 and 4 revealed a grain size of 22 , 39 and $25 \mu \mathrm{m}$ respectively. Except for alloy-3 a refinement in grain size was observed with alloying. This refinement in microstructure during solidification by the use of alloying is in agreement with literature [42]. The presence of grain boundary precipitates in alloy-2 and alloy-4 may have helped in a greater grain refinement during solidification as compared to alloy-1 and alloy-3.

50\% Rolled Samples. The microstructures of the four alloys obtained after 50\% rolling reduction are provided in Fig. 3(a-d). The evidence of stored energy as a result of rolling can be seen in all the deformed microstructures by the presence of twins. The formation of twins during rolling at $300{ }^{\circ} \mathrm{C}$ of magnesium alloy, AZ31, is reported in literature. These twins may be helpful for dynamic recrystallization depending upon the processing conditions. Literature reports the nucleation of dynamic recrystallized (DRXed) grains at twins [43,44].

The evidence of recrystallization (RX) is seen in first three alloys as small (newly formed) and large (coarsened) grains are visible in all four alloys. However, due to inter-pass annealing the RXed grains cannot be accurately classified into DRXed or SRXed grains. There are different nucleation sources of RXed grains i.e., deformed grains, shear bands, particle simulated nucleation (PSN) and twins [45-47]. As compared with their as-cast counterparts, second phase particles are visible in alloy-2,3 and 4, but their fraction is significantly decreased for alloy-1. It reflects that the second phase particles seen in alloys-2, 3 and 4 are thermally stable at the rolling temperature of $300{ }^{\circ} \mathrm{C}$. The grain size observed after rolling is, $10,6,9$ and $28 \mu \mathrm{m}$ respectively for alloy- 1 to 4 . It is evident from these results that rolling reduced overall grain size in all alloy compositions except for alloy-4 whose grain size remain almost unaltered. This may be an indication of some pinning effect in AgIn containing alloy. 

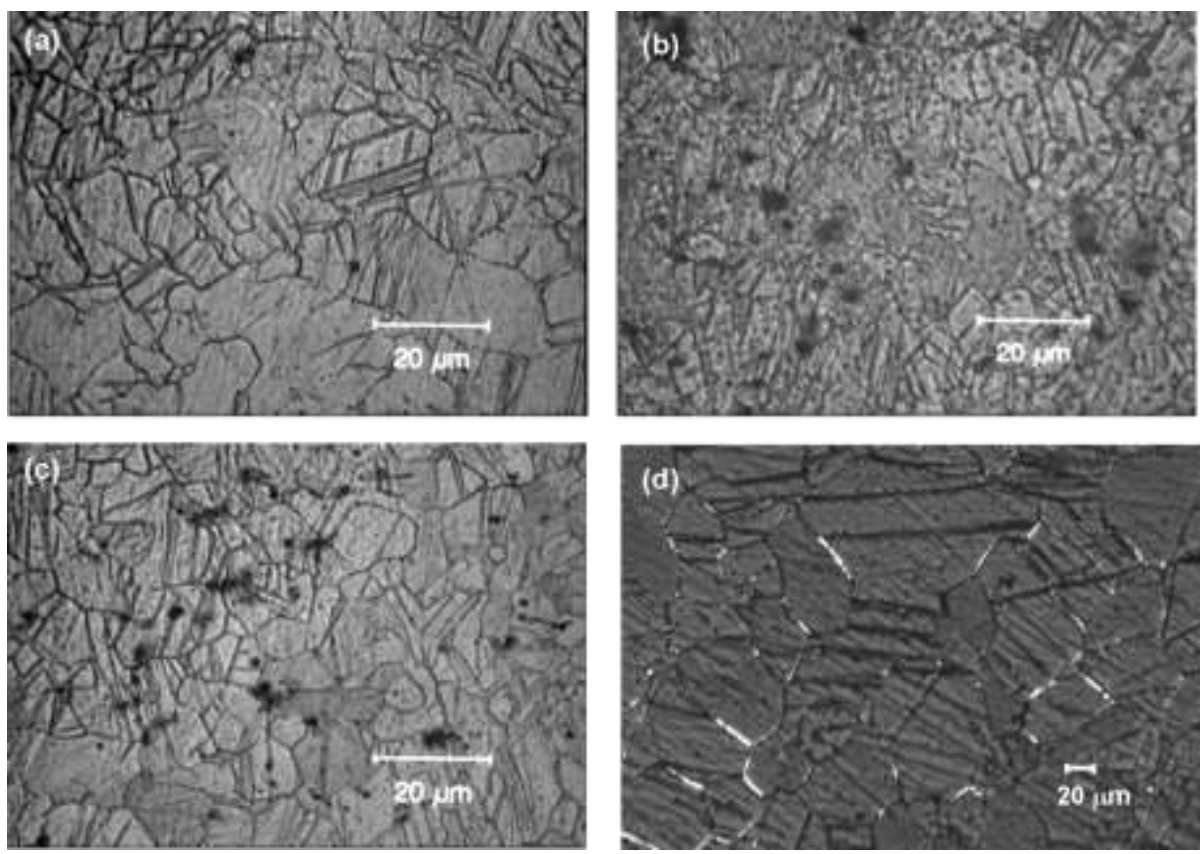

Fig. 3. As-rolled 50\% samples (a) alloy-1, (b) alloy-2, (c) alloy-3, and (d) alloy-4.

75\% Rolled Samples. The microstructures of the four alloys obtained after $75 \%$ rolling reduction are provided in Fig. 4(a-d). At this rolling reduction, second phase particles are still observable in alloy-2, 3 and 4 but have completely vanished for alloy-1. This observation further strengthens the thesis that the observed phase in alloy- 1 was $\mathrm{Mg} 17 \mathrm{Al12}$, which has dissolved into the matrix at rolling/ inter-pass temperature of $300{ }^{\circ} \mathrm{C}$. Literature reports that $\mathrm{Mg} 17 \mathrm{Al1} 2$ second phase particles dissolve in matrix at temperatures in excess of $200{ }^{\circ} \mathrm{C}$ [41]. The presence of deformation twins is still evident in all microstructures. After deformation, the coarse grains containing twins have more stored energy as compared to the fine twin-free grains. The type of the individual twins cannot be classified using the optical micrographs alone and need Schmid factor EBSD based analysis. There is a slight decrease in the grain size of alloy-4 with the appearance of some fine grains, this may be an indication of the start of recrystallization in this alloy.

90\% Rolled Samples. The microstructures the four alloys obtained after 90\% rolling reduction are provided in Fig. 5(a-d). The microstructures of alloy-1, 2 and 3 suggest completion of recrystallization as grains are almost equiaxed. The grain size of alloy-4 is still $\sim 19 \mu \mathrm{m}$ which is not much different from $\sim 21 \mu \mathrm{m}$ size observed after $75 \%$ rolling. This observation may be an indication of the continuation of recrystallization besides the strong pinning effect of the precipitates in alloy- 4 and their thermal stability.

Comparison of As-cast and As-rolled Grains. The average grain size of four alloys in the as-cast condition and after three rolling reductions are provided in Table 1 . The separate additions of 0.5 wt. $\% \mathrm{Ag}$ and $\mathrm{AgIn}$ respectively refined the as-cast structure of the $\mathrm{Mg}-3 \mathrm{Al}-1 \mathrm{Zn}$ alloy. However, the same addition of In did not help in refining the as-cast microstructure. However, all three alloying additions helped in recrystallization and thus in refining the rolled microstructure. The evidence of RX was observed for alloy- 2 to 3 at $50 \%$ reduction while for alloy-4 it only appeared after $75 \%$ reduction. The combined effect of AgIn with the increase in percentage deformation was a slow and gradual decrease in grain size. This refinement in microstructure by the use of alloying is in agreement with literature [42]. Literature reports that alloying additions which serve as strong refiners, in as cast microstructure, facilitate $\langle\mathrm{c}+\mathrm{a}\rangle$ non-basal slip during TMP which in term is beneficial for dynamic recrystallization and weakens basal texture [48]. 

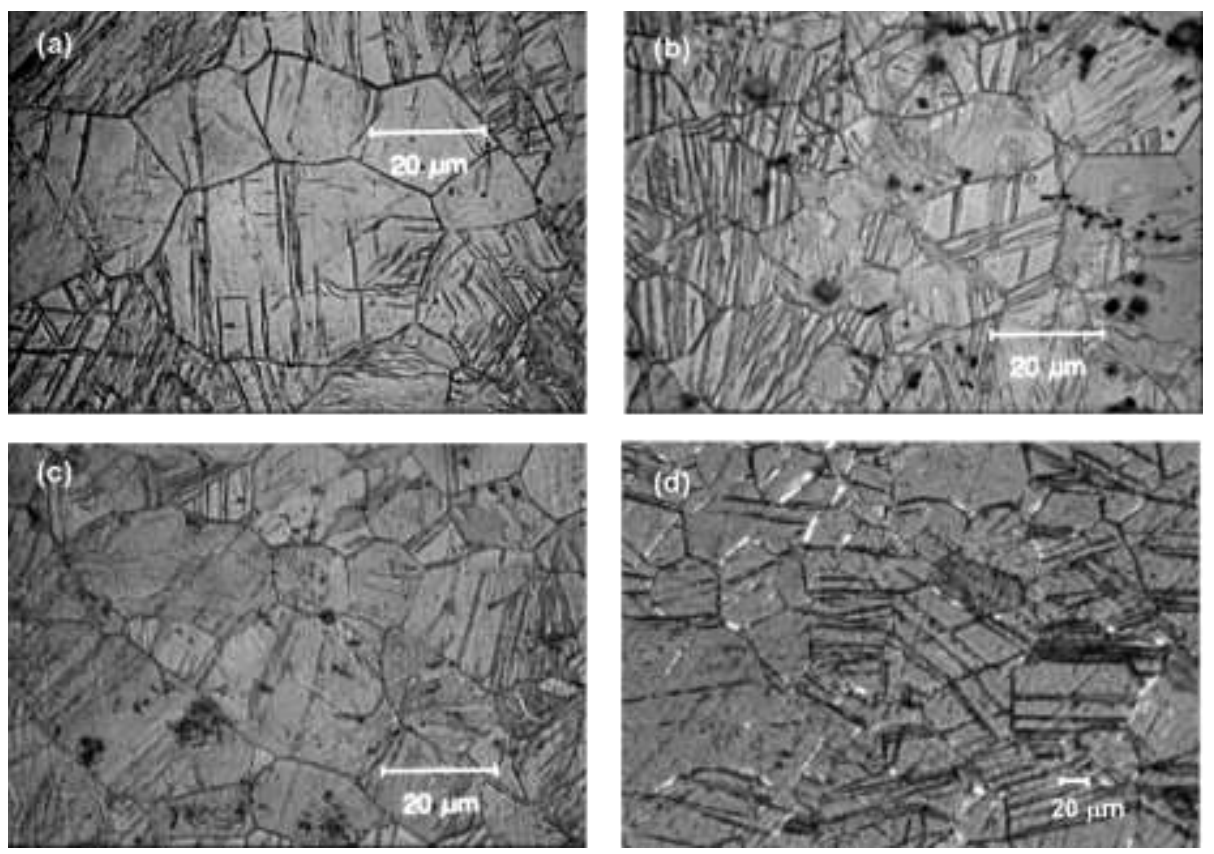

Fig. 4. As-rolled 75\% -rolled samples (a) alloy-1, (b) alloy-2, (c) alloy-3, and (d) alloy-4.
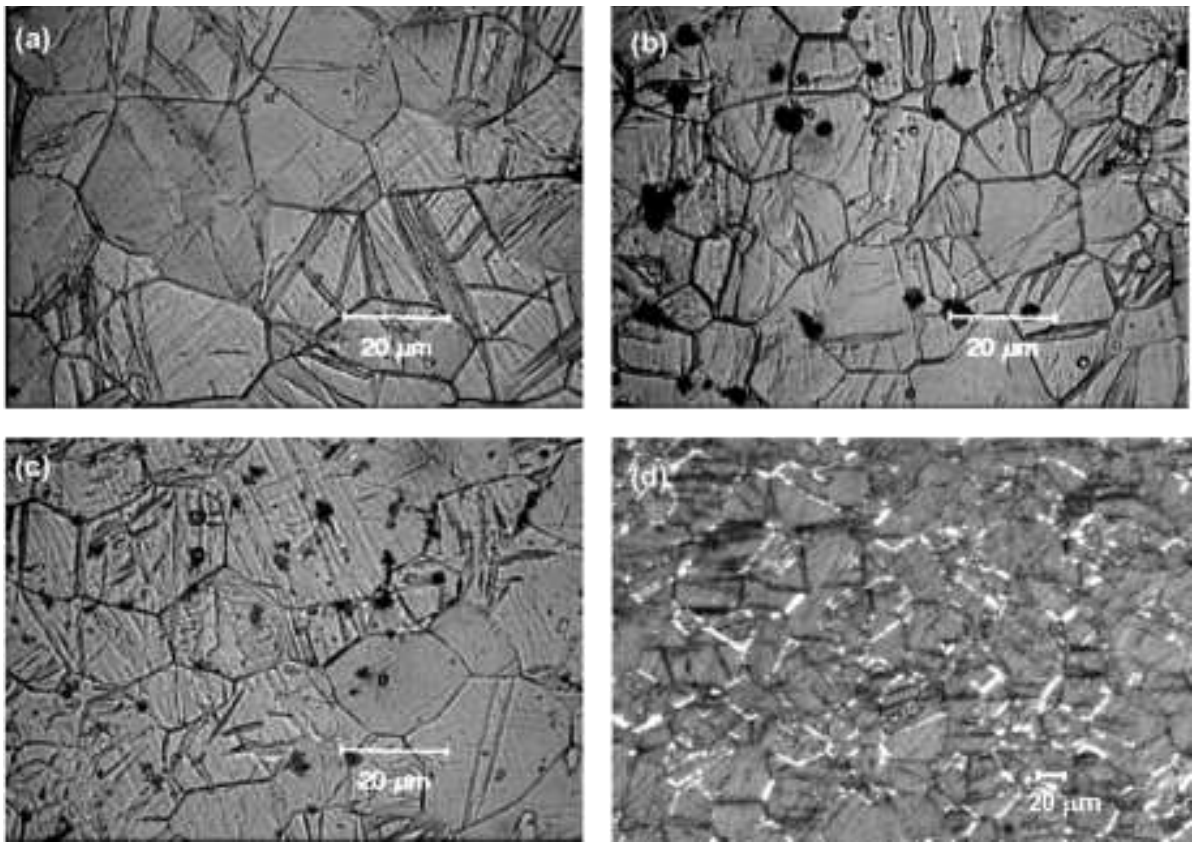

Fig. 5. As-rolled 90\% samples (a) alloy-1, (b) alloy-2, (c) alloy-3, and (d) alloy-4.

Table 1 . The grain size of alloys $1,2,3$ and $4[\mu \mathrm{m}]$.

\begin{tabular}{|l|c|c|c|c|}
\hline & As-cast & $\mathbf{5 0 \%}$ Rolled & $\mathbf{7 5 \%}$ Rolled & 90\% Rolled \\
\hline Alloy-1 & 33 & 10 & 15 & 13 \\
\hline Alloy-2 & 22 & 6 & 14 & 12 \\
\hline Alloy-3 & 39 & 9 & 16 & 14 \\
\hline Alloy-4 & 25 & 28 & 21 & 19 \\
\hline
\end{tabular}

XRD Phase Analysis. XRD was employed to identify the phases found in the as-cast structure, Fig. 6. The Mg-base solid solution matrix is confirmed in all alloys with almost identical peak position. Owing to the very small alloying additions $(0.5 \mathrm{wt} . \%)$ the volume fraction of the second phase formed is very small in each case. Although the second phase particles were visible in both $\mathrm{OM}$ and SEM but were below the detection limit of XRD. SEM/EDX analysis was employed to obtain more data about the second phase particles in alloy- 4 . 


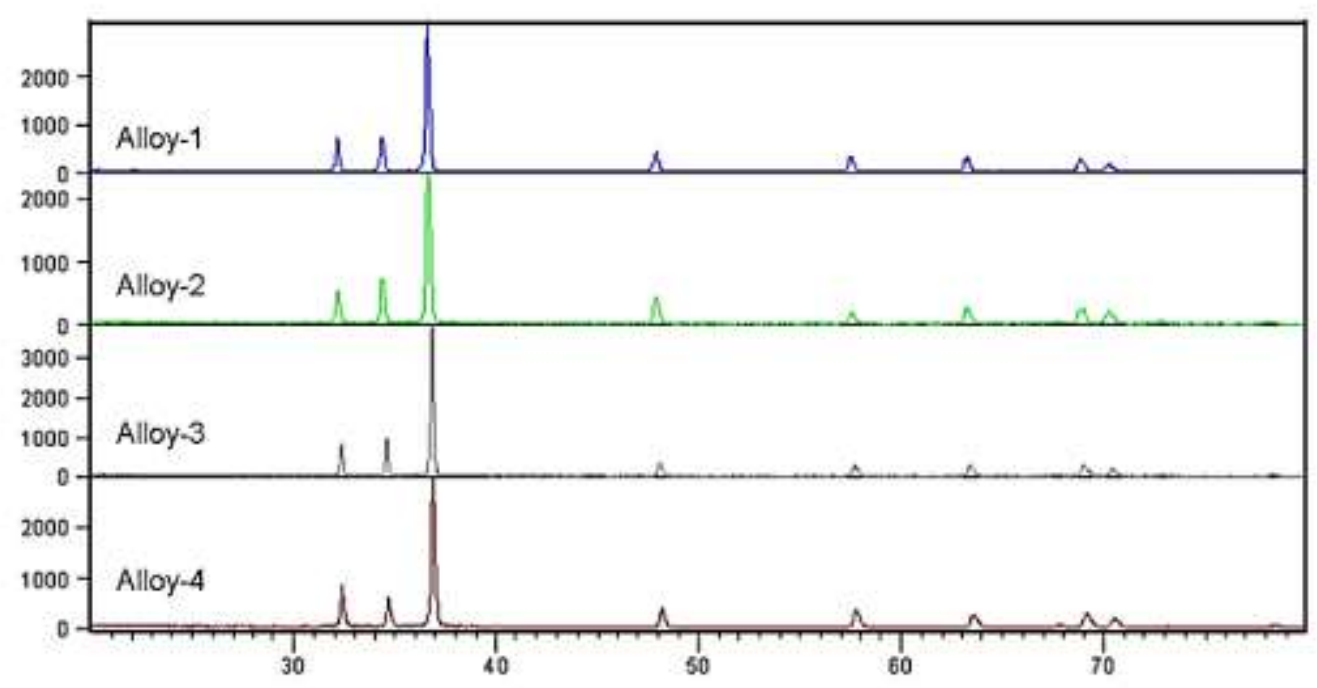

Fig. 6. XRD analysis of the as-cast alloys.

EDX Analysis. Fig. 7(a,b) provides the SEM back scattered electron image and EDX analysis of alloy-4 in the $75 \%$ rolled condition, respectively. Two different regions, namely region-A (matrix) and region-B (precipitate) were selected. The matrix phase shows the presence of both $\mathrm{Ag}$ and In in the solid solution while only Ag is found in the precipitates.

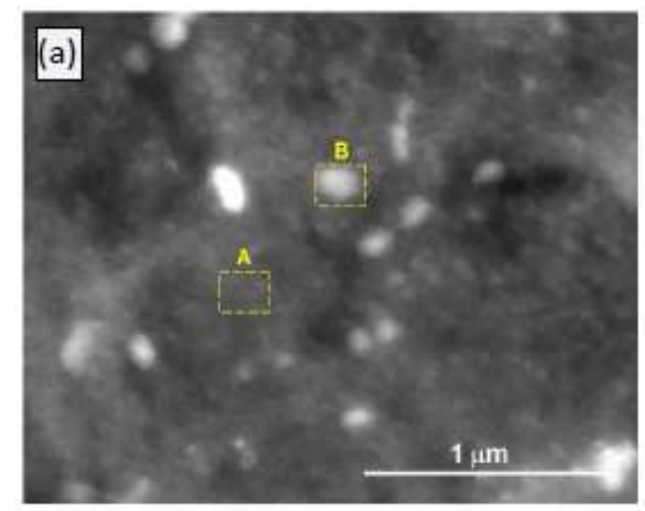

(b)

\begin{tabular}{|c|c|c|}
\hline Elements & Region A (wt.\%) & Region B (wt.\%) \\
\hline $\mathrm{Al}$ & 2.18 & 3.05 \\
\hline $\mathrm{Mg}$ & 96.01 & 95.02 \\
\hline $\mathrm{Zn}$ & 1.17 & 1.46 \\
\hline $\mathrm{Ag}$ & 0.54 & 0.47 \\
\hline $\mathrm{In}$ & 0.10 & 0 \\
\hline
\end{tabular}

Fig. 7. SEM/ EDS analysis of alloy-4 in the $75 \%$ rolled condition.

XRD Macrotexture. Fig. 8 (a-d) provides the (0002) pole figure of alloy-1 to alloy-4 which reveal the macrotexture evolution after 50, 75 and 90\% reductions respectively. Fig. 8(a) and 8(d) represent that the basal pole textures of alloy-1 and alloy-4 are almost similar for identical reductions. The results reveal that angular distribution of basal poles is more towards TD than RD in both alloys at all reductions. This planar anisotropy is reported to influence the mechanical properties of the as-rolled sheets. In a study of the previous researchers, same planar anisotropy was reported after single pass $(15,20,25 \& 30 \%)$ reduction of AZ31 sheet, but in that study the basal poles were inclined more to RD as compared to TD. The increased inclination of basal poles to a particular direction was associated with high Schmid factor to that direction i.e. the flow stresses are lesser in that direction [49]. However, the observed basal poles intensity of alloy-1 is less as compared to alloy- 4 at each respective reduction but the general features of the pole figure do not alter.

On the other hand, no prominent angular distribution of basal planes to either RD or TD is observed in alloy-2 and alloy-3, Fig. 8(b) and (c). The texture formed in alloy-2 and alloy-3 is strong as compared to alloy- 1 and alloy- 4 . These alloys reveal a typical rolled $\mathrm{Mg}$ sheet texture with their basal planes parallel to the sheet plane. The (0002) basal pole figure revealed an increased concentration of basal poles towards the ND, showing concentric contours [50]. A stronger (0002) fiber texture was formed along the normal direction ND in alloy- 2 and alloy-3 which may be an indication that basal slip is one of the major deformation modes in these alloys. 
(a)
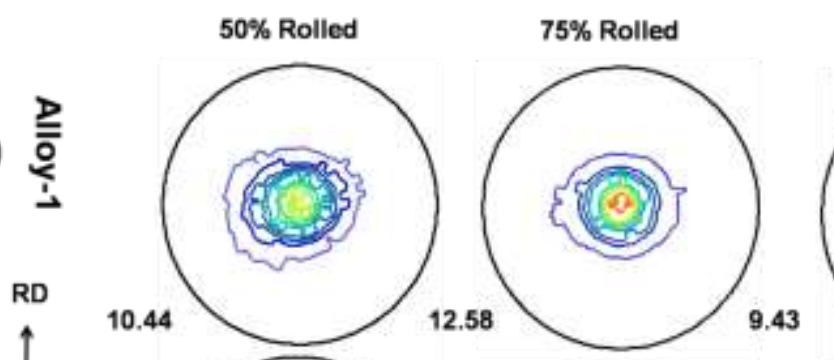

$90 \%$ Rolled

(b)

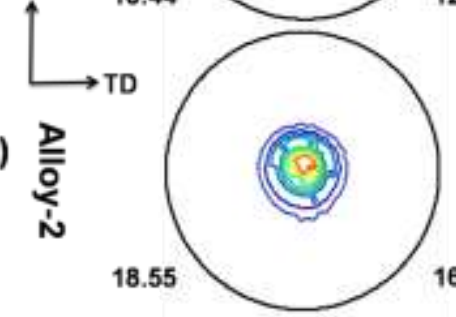

${ }^{204}$

9.43

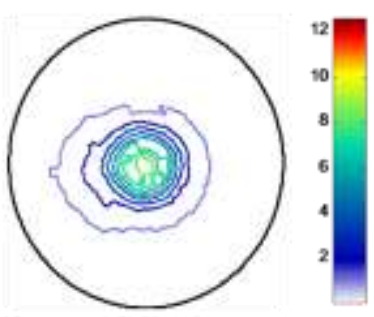

(c)
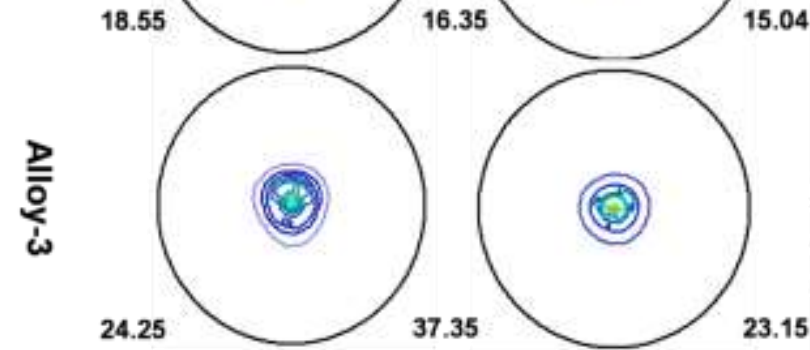

5.04

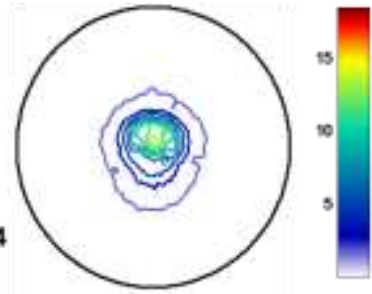

(d)
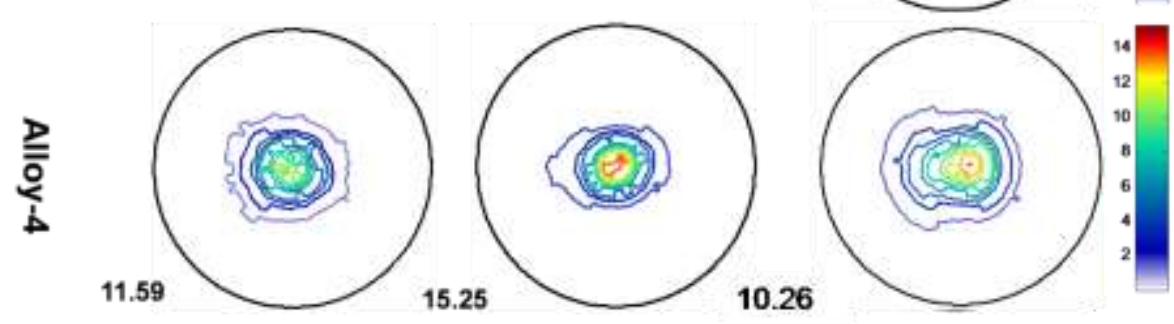

Fig. 8. The (0002) pole figure of alloy-1 to alloy- 4 after 50, 75 and $90 \%$ reductions.

The results of basal poles intensities after 50, 75 and $90 \%$ rolling reduction are summarized in Fig. 9. It reveals that the basal pole intensity of alloy-1 remained minimum during all parentages of rolling reduction as compared to its competitors. The common feature of alloy-1, 3 and 4 is that at $75 \%$ there is an increase in the basal texture intensity which reduced as the reduction was further increased to $90 \%$. It is reported in the literature that a stronger texture is normally associated with grain coarsening [50]. Since alloy-1 and ally-4 showed almost similar basal texture during preset rolling schedule, these two alloys were selected for mechanical testing.

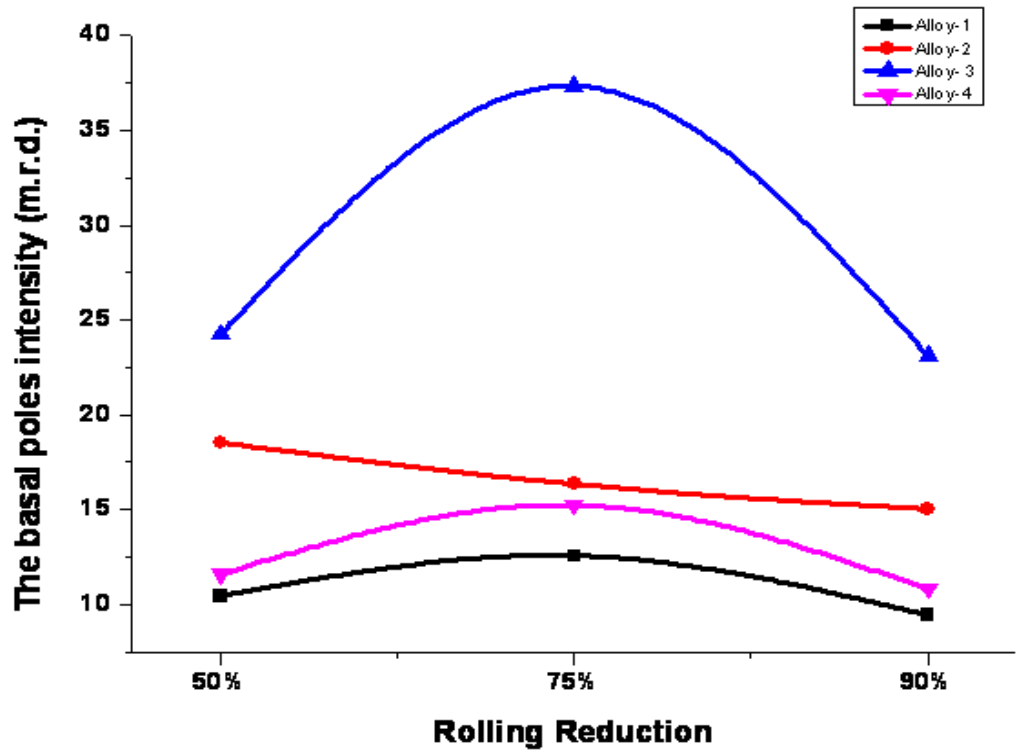

Fig. 9. The peak intensity plots of (0002) pole figure for alloy-1 to alloy-4 after 50, 75 and $90 \%$ reductions. 


\section{Summary}

In summary, rollability, microstructure and texture evolution in four different alloys sheets processed by multi-pass warm rolling with inter-pass heating at fixed temperature and time were investigated. Crack free sheets of less than $1 \mathrm{~mm}$ thickness were produced successfully from all four alloys under the designed processing parameters. All alloys showed grain refinement of their as cast microstructure, however, all except alloy-4, showed a slight scatter in grain sizes after rolling reductions of 50, 75 and $90 \%$. A sustained decrease in grain size with increasing the rolling reductions was only observed in alloy-4. XRD macrotexture results of alloy-2 and 3 presented very strong basal texture showing almost concentric contours around normal direction (ND). Such strong sheet texture is attributed to a preferential alignment of basal planes parallel to the sheet surface. On the other hand alloy-1 and alloy-4 revealed a weaker texture with basal poles spread more towards transverse direction (TD) as compared to rolling direction (RD) and may be due to the activation of some $<c+a>$ non-basal slip and twinning in addition to basal slip. Such difference in microstructure and texture of four alloys was attributed to sensitivity of alloys compositions to process temperature, reduction per pass, inter-pass heating cycles and cooling after rolling.

\section{Acknowledgements}

The corresponding author would like to acknowledge the funding provided by the higher education commission (HEC) of Pakistan under the international research initiative support program (IRSIP). All the research support provided by the faculty and staff at school of materials in the university of Manchester is also gratefully acknowledged.

\section{References}

[1] E. Aghion, B. Bronfin, Magnesium alloys development towards the 21st century, in: Mater. Sci. Forum, Trans. Tech. Publ., 350 (2000) 19-30.

[2] M.M. Avedesian, H. Baker, ASM specialty handbook: magnesium and magnesium alloys, ASM Int., 1999.

[3] D. Carou, E.M. Rubio, J.P. Davim, Machinability of Magnesium and its Alloys: A Review, in: Traditional Machining Processes, Springer, Berlin, 2015, pp. 133-152.

[4] K. Lee, C. Kang, K. Kim, Effect of hot working on the damping capacity and mechanical properties of AZ31 magnesium alloy, in: IOP Conf. Ser.: Mater. Sci. Eng., 82 (2015) 012114.

[5] D.-G. Kim, K.-M. Lee, J.-S. Lee, Y.-O. Yoon, H.-T. Son, Evolution of microstructures and textures in magnesium AZ31 alloys deformed by normal and cross-roll rolling, Mater. Lett., 75 (2012) 122-125.

[6] X. Huang, K. Suzuki, A. Watazu, I. Shigematsu, N. Saito, Mechanical properties of Mg-Al-Zn alloy with a tilted basal texture obtained by differential speed rolling, Mater. Sci. Eng., A, 488 (2008) 214-220.

[7] H. Somekawa, T. Mukai, Effect of texture on fracture toughness in extruded AZ31 magnesium alloy, Scripta Mater., 53 (2005) 541-545.

[8] S.-H. Kim, B.-S. You, C.D. Yim, Y.-M. Seo, Texture and microstructure changes in asymmetrically hot rolled AZ31 magnesium alloy sheets, Mater. Lett., 59 (2005) 3876-3880.

[9] S.R. Agnew, M.H. Yoo, C.N. Tome, Application of texture simulation to understanding mechanical behavior of $\mathrm{Mg}$ and solid solution alloys containing Li or Y, Acta Mater., 49 (2001) 4277-4289. 
[10] S. Sandlöbes, S. Zaefferer, I. Schestakow, S. Yi, R. Gonzalez-Martinez, On the role of nonbasal deformation mechanisms for the ductility of $\mathrm{Mg}$ and $\mathrm{Mg}-\mathrm{Y}$ alloys, Acta Mater., 59 (2011) 429-439.

[11] S.R. Agnew, O. Duygulu, A mechanistic understanding of the formability of magnesium: Examining the role of temperature on the deformation mechanisms, Trans. Tech. Publ., 419 (2012) 177-188.

[12]R. Sánchez-Martín, C. Zambaldi, M.T. Pérez-Prado, J.M. Molina-Aldareguia, High temperature deformation mechanisms in pure magnesium studied by nanoindentation, Scripta Mater., 104 (2015) 9-12.

[13]P. Hidalgo-Manrique, V. Herrera-Solaz, J. Segurado, J. Llorca, F. Gálvez, O.A. Ruano, S.B. Yi, M.T. Pérez-Prado, Origin of the reversed yield asymmetry in Mg-rare earth alloys at high temperature, Acta Mater., 92 (2015) 265-277.

[14]A. Vinogradov, D. Orlov, A. Danyuk, Y. Estrin, Deformation mechanisms underlying tensioncompression asymmetry in magnesium alloy ZK60 revealed by acoustic emission monitoring, Mater. Sci. Eng., A 621 (2015) 243-251.

[15] J. Hirsch, T. Al-Samman, Superior light metals by texture engineering: Optimized aluminum and magnesium alloys for automotive applications, Acta Mater., 61 (2013) 818-843.

[16]X. Huang, K. Suzuki, Y. Chino, Annealing behaviour of Mg-3Al-1Zn alloy sheet obtained by a combination of high-temperature rolling and subsequent warm rolling, J. All. Comp., 509 (2011) 4854-4860.

[17] I. Ulacia, S. Yi, M.T. Pérez Prado, N.V. Dudamell, F. Galvez Diaz-Rubio, D. Letzig, I. Hurtado, Texture evolution of AZ31 magnesium alloy sheet at high strain rates, (2010).

[18] A. Styczynski, C. Hartig, J. Bohlen, D. Letzig, Cold rolling textures in AZ31 wrought magnesium alloy, Scripta Mater., 50 (2004) 943-947.

[19] X. Huang, K. Suzuki, Y. Chino, Different annealing behaviours of warm rolled Mg-3Al-1Zn alloy sheets with dynamic recrystallized microstructure and deformation microstructure, Mater. Sci. Eng., A 560 (2013) 232-240.

[20]X. Yang, Y. Okabe, H. Miura, T. Sakai, Effect of prior strain on continuous recrystallization in AZ31 magnesium alloy after hot deformation, Mater. Sci. Eng., A 535 (2012) 209-215.

[21]X. Huang, K. Suzuki, A. Watazu, I. Shigematsu, N. Saito, Effects of thickness reduction per pass on microstructure and texture of $\mathrm{Mg}-3 \mathrm{Al}-1 \mathrm{Zn}$ alloy sheet processed by differential speed rolling, Scripta Mater., 60 (2009) 964-967.

[22]X. Huang, K. Suzuki, A. Watazu, I. Shigematsu, N. Saito, Microstructural and textural evolution of AZ31 magnesium alloy during differential speed rolling, J. All. Comp., 479 (2009) 726-731.

[23] S.R. Agnew, P. Mehrotra, T.M. Lillo, G.M. Stoica, P.K. Liaw, Crystallographic texture evolution of three wrought magnesium alloys during equal channel angular extrusion, Mater. Sci. Eng., A 408 (2005) 72-78.

[24] R. Lapovok, L.S. Tóth, A. Molinari, Y. Estrin, Strain localisation patterns under equal-channel angular pressing, J. Mech. Phy. Sol., 57 (2009) 122-136.

[25]P. Serre, R.B. Figueiredo, N. Gao, T.G. Langdon, Influence of strain rate on the characteristics of a magnesium alloy processed by high-pressure torsion, Mater. Sci. Eng., A 528 (2011) 36013608 .

[26] H. Wang, P.D. Wu, J. Wang, Modeling inelastic behavior of magnesium alloys during cyclic loading-unloading, Int. J. Plast., 47 (2013) 49-64. 
[27]A.N. Albakri, B. Mansoor, H. Nassar, M.K. Khraisheh, Thermo-mechanical and metallurgical aspects in friction stir processing of AZ31 Mg alloy-A numerical and experimental investigation, $\mathrm{J}$. Mater. Proc. Tech., 213 (2013) 279-290.

[28]B. Song, G. Huang, H. Li, L. Zhang, G. Huang, F. Pan, Texture evolution and mechanical properties of AZ31B magnesium alloy sheets processed by repeated unidirectional bending, J. All. Comp., 489 (2010) 475-481.

[29] N. Li, G. Huang, R. Xin, Q. Liu, Effect of initial texture on dynamic recrystallization and deformation mechanisms in AZ31 Mg alloy extruded at 573K, Mater. Sci. Eng., A 569 (2013) 1826.

[30] X. Huang, K. Suzuki, Y. Chino, Static recrystallization and mechanical properties of Mg-4Y3RE magnesium alloy sheet processed by differential speed rolling at 823K, Mater. Sci. Eng., A 538 (2012) 281-287.

[31] N. Stanford, M.D. Callaghan, B. de Jong, The effect of rare earth elements on the behaviour of magnesium-based alloys: Part 1-Hot deformation behaviour, Mater. Sci. Eng., A 565 (2013) 459468.

[32] R. Li, F. Pan, B. Jiang, Q. Yang, A. Tang, Effects of combined additions of Li and Al-5Ti-1B on the mechanical anisotropy of AZ31 magnesium alloy, Mater., Des. 46 (2013) 922-927.

[33]H. Borkar, M. Pekguleryuz, Microstructure and texture evolution in $\mathrm{Mg}-1 \% \mathrm{Mn}-\mathrm{Sr}$ alloys during extrusion, J. Mater. Sci., 48 (2013) 1436-1447.

[34] M. Pekguleryuz, M. Celikin, M. Hoseini, A. Becerra, L. Mackenzie, Study on edge cracking and texture evolution during $150{ }^{\circ} \mathrm{C}$ rolling of magnesium alloys: the effects of axial ratio and grain size, J. All. Comp., 510 (2012) 15-25.

[35] M. Pekguleryuz, M. Avedesian, Magnesium alloying-Some metallurgical aspects, Magnesium alloys and their applications, (1992) 213-220.

[36] S.N. Murty, N. Nayan, S. Sharma, K.S. Kumar, P. Sinha, Development of ultrafine-grained magnesium alloy AZ31 by multi-pass warm rolling, Met. Sci. Heat Treat., 53 (2011) 270-273.

[37] J. Yan, Y. Sun, F. Xue, S. Xue, W. Tao, Microstructure and mechanical properties in cast magnesium-neodymium binary alloys, Mater. Sci. Eng., A 476 (2008) 366-371.

[38]Z. Yazhong, P. Fusheng, P. Jian, W. Weiqing, L. Suqin, Effect of neodymium on the asextruded ZK20 magnesium alloy, J. Rare Earths, 28 (2010) 631-635.

[39] L. Mackenzie, M. Pekguleryuz, The influences of alloying additions and processing parameters on the rolling microstructures and textures of magnesium alloys, Mater. Sci. Eng., A 480 (2008) 189-197.

[40]Z.B. Sajuri, Y. Miyashita, Y. Hosokai, Y. Mutoh, Effects of Mn content and texture on fatigue properties of as-cast and extruded AZ61 magnesium alloys, Int. J. Mech. Sci., 48 (2006) 198-209.

[41]C. Bettles, M. Barnett, Advances in wrought magnesium alloys, in, Cambridge: Woodhead Publishing, 2012.

[42] J. Du, J. Yang, M. Kuwabara, W. Li, J. Peng, Effects of carbon and/or alkaline earth elements on grain refinement and tensile strength of AZ31 alloy, Mater. Trans., 49 (2008) 2303-2309.

[43] N.J. Park, C.W. Ha, Effect of initial texture on the development of microstructure and mechanical properties in AZ31 magnesium alloy after rolling at $300 \mathrm{C}$, in: Applied Mechanics and Materials, Trans. Tech. Publ., 217 (2012) 354-357.

[44]A.G. Beer, M.R. Barnett, The influence of twinning on the hot working flow stress and microstructural evolution of magnesium alloy AZ31, in: Mater. Sci. Forum, Trans. Tech. Publ., 488 (2005) 611-614. 
[45]N. Stanford, M. Barnett, The origin of rare earth texture development in extruded Mg-based alloys and its effect on tensile ductility, Mater. Sci. Eng., A 496 (2008) 399-408.

[46] J. Robson, D. Henry, B. Davis, Particle effects on recrystallization in magnesium-manganese alloys: Particle-stimulated nucleation, Acta Mater., 57 (2009) 2739-2747.

[47] K. Yu, S.-T. Rui, X.-Y. Wang, R.-C. Wang, W.-X. Li, Texture evolution of extruded AZ31 magnesium alloy sheets, Trans. Nonferr. Met. Soc. China, 19 (2009) 511-516.

[48]T. Al-Samman, Comparative study of the deformation behavior of hexagonal magnesiumlithium alloys and a conventional magnesium AZ31 alloy, Acta Mater., 57 (2009) 2229-2242.

[49]D. Liu, Z. Liu, E. Wang, Effect of rolling reduction on microstructure, texture, mechanical properties and mechanical anisotropy of AZ31 magnesium alloys, Mater. Sci. Eng., A 612 (2014) 208-213.

[50] M. Kohzu, K. Kii, Y. Nagata, H. Nishio, K. Higashi, H. Inoue, Texture randomization of AZ31 magnesium alloy sheets for improving the cold formability by a combination of rolling and hightemperature annealing, Mater. Trans., 51 (2010) 749-755. 